\title{
Effect of Opium Dependency on Burn Healing in a Rat Model: An Experimental Study
}

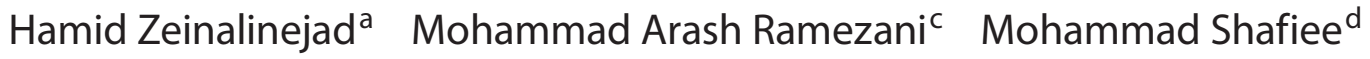 \\ Mohsen Karvar ${ }^{a}$ Reza Malekpour-Afshar ${ }^{b}$ \\ Departments of a Surgery and ${ }^{b}$ Pathology, Kerman University of Medical Sciences, Kerman, ${ }^{\mathrm{C}}$ Isfahan Cardiovascular \\ Research Center, Isfahan University of Medical Sciences, Isfahan, and dDepartment of Surgery, Shahid Beheshti \\ University of Medical Sciences, Tehran, Iran
}

\section{Key Words}

Burn $\cdot$ Opium $\cdot$ Rat model $\cdot$ Thermal injury $\cdot$ Wound healing

\begin{abstract}
Objective: This study aimed to investigate the effect of opium dependency on the healing of third-degree burns in rats. Material and Methods: Twenty-four rats were randomly divided to experimental and control groups. In the experimental group, opium was added to the drinking water for 21 days at increasing concentrations. The control group did not receive opium. To prove dependency on opium in the rats, naloxone was injected intraperitoneally. Full-thickness burn wounds were inflicted by applying an iron cuboid preheated to $94^{\circ} \mathrm{C}$ to the flank of all rats for $20 \mathrm{~s}$. On day 14 after burn injury, full-thickness biopsies were taken. Blind histopathologic evaluation was performed to assess length and thickness of the re-epithelialization area, number of neutrophils, fibroblasts, mononuclear cells and new vessels, and percentage of tissue in repair (neutrophilic exudate, and granulation and fibrous tissue). Findings were analyzed using SPSS software. Results: The wound surface area was $95 \pm 43.35 \mathrm{~mm}^{2}$ in the control group and $120.4 \pm 50.12 \mathrm{~mm}^{2}$ in the experimental group $(p=0.224)$. The findings show that opium de-
\end{abstract}

pendency has no significant effect on the healing of burn wounds in rats except for the number of monocytes on day $14(p<0.05)$. Conclusion: Morphine dependency does not seem to be as effective on third-degree burn healing.

Copyright $\odot 2011$ S. Karger AG, Basel

\section{Introduction}

The prevalence of thermal injury is high in Iran, insofar as different studies have indicated incidence rates of burn hospitalization ranging from 13.5 to 21.6 per 100,000 person-years $[1,2]$. Many intrinsic and extrinsic factors affect healing of burn wounds. Physiologic or biochemical defects can delay or impair the healing process and cause later complications [3].

Opioids are the preferred treatment for controlling pain in burn patients both for the initial injury and for procedures such as wound debridement and changing dressings [4,5]. On the other hand, opium is a common form of substance abuse in Iran. In 2004, a study using unlinked anonymous urine drug testing was performed in a medical center in Kerman, the biggest province in Iran. In this study $14.4 \%$ of urine samples were positive

\section{KARGER}

Fax +4161306 1234

E-Mail karger@karger.ch

www.karger.com
(C) 2011 S. Karger AG, Basel

$1011-7571 / 11 / 0202-0147 \$ 38.00 / 0$

Accessible online at:

www.karger.com/mpp
Mohammad Arash Ramezani

Surveillance Department, Isfahan Cardiovascular Research Center

Jomhoori Square, Khorram Street

Isfahan, 8187698191 (Iran)

Tel. +98 9131412 932, Fax +98 311337 3435, E-Mail arash98@ gmail.com 
for opioid metabolites [6]. A study by Santos et al. [7] showed that burn patients were more likely to have drug abuse.

Previous studies have investigated the effect of opioids on the healing process of wounds, with both positive and negative effects. Opioids mediate wound healing probably by altering the inflammatory milieu of wounds [810]. Morphine suppresses monocyte chemotaxis and inhibits cytolytic activity of natural killer cells and proliferative responses of lymphocytes to mitogens, which can potentially impair wound healing [11-13]. However, there is little research on the effect of opioids on the healing of burn wounds. As a better understanding of the relationship between opioid dependency and burn healing will likely contribute towards the understanding of the role of opioids, we decided to study the effect of opium dependency on the healing of burns in an animal model.

\section{Materials and Methods}

\section{Experimental Animals}

Twenty-four female non-pregnant Sprague-Dawley rats with an average weight of $210 \pm 20 \mathrm{~g}$ were randomly divided into two groups, experimental and control groups, with 12 rats in each group. The temperature, food and rearing conditions of both groups were similar. Experimental procedures on animals, which were approved by the Ethics Committee, Kerman University of Medical Sciences, were in accordance with the guidelines for the care and use of laboratory animals [14].

\section{Opium Dependency}

The experimental group of rats received opium tablets dissolved in drinking water, while rats in the control group received water without any additive. Opium tablets were produced by $\mathrm{Da}$ roupakhsh, Tehran, Iran (containing $100 \mathrm{mg}$ opium, equivalent to $10 \%$ morphine). In the first $48 \mathrm{~h}$, opium tablets $(1 \mathrm{mg} / \mathrm{ml})$ were added to the rats' drinking water. The concentration of opium in water was increased every $48 \mathrm{~h}$ to 2,3 and $4 \mathrm{mg} / \mathrm{ml}$ and continued at $4 \mathrm{mg} / \mathrm{ml}$ to the end of the study. The rats drank opium-containing water without adding sucrose or sodium chloride [15].

\section{Opium Withdrawal Syndrome}

To confirm opium dependency in our rat samples, we used naloxone - a morphine antagonist - and detected the withdrawal signs in all rats sampled. The withdrawal symptoms consisted of: writhing, ptosis, diarrhea, jumping, teeth chattering, paw tremor, chewing, and head and wet-dog shaking [16]. To achieve this, on day 21, 1 rat was selected randomly from each group and naloxone ( $2 \mathrm{mg} / \mathrm{kg}$; Daroupakhsh) was injected intraperitoneally. The rats were observed for $20 \mathrm{~min}$ for the naloxone-precipitated withdrawal syndrome. The aforementioned symptoms were assessed in experimental and control samples. Opium dependency of rats in experimental and control groups was verified.
Table 1. Results of the withdrawal test with naloxone in experimental and control rats

\begin{tabular}{lcl}
\hline Withdrawal signs & $\begin{array}{c}\text { Opium-dependent } \\
\text { group }\end{array}$ & Control group \\
\hline Writhing & $0 / 10$ & \\
Ptosis & $10 / 10$ & $0 / 10$ \\
Diarrhea & $8 / 10$ & $0 / 10$ \\
Jumping & $0 / 10$ & $0 / 10$ \\
Teeth chattering & $9 / 10$ & $0 / 10$ \\
Paw tremor & $0 / 10$ & $0 / 10$ \\
Chewing & $10 / 10$ & $0 / 10$ \\
Head shaking & $10 / 10$ & $0 / 10$ \\
Wet-dog shaking & $8 / 10$ & $0 / 10$ \\
& & $0 / 10$
\end{tabular}

\section{Thermal Injury Model}

On day 21, the rats were anesthetized using $25 \mathrm{mg}$ of intraperitoneal ketamine (Daroupakhsh). The rats were completely anesthetized for $10 \mathrm{~min}$ and got full consciousness after 30$45 \mathrm{~min}$. This time was enough for shaving hair and inducing burn. The hair in the flank area was cut using an electric hair clipper (Moser, model 1400) to fully remove hair. A preliminary pilot study was performed on 3 rats to define the anesthetic drug dosage and the temperature needed to induce a third-degree burn.

For burn induction, four iron cuboids measuring $2 \times 2 \times$ $3 \mathrm{~cm}$ with a $7-\mathrm{cm}$ handle weighing $100 \mathrm{~g}$ were used. The cuboids were heated for $2 \mathrm{~h}$ in a water bath containing boiling water at $94^{\circ} \mathrm{C}$ (the temperature of boiling water in Kerman). Cuboids were heated for $30 \mathrm{~min}$ after burn induction and were used again. The anesthetized rat was kept on one side on a board. The heated and wet cuboid was put on the shaved flank area vertically. It was kept for $20 \mathrm{~s}$ with a minimum pressure in place without any extra pressure. This led to a third-degree burn measuring $2 \times 2 \mathrm{~cm}$ $\left(400 \mathrm{~mm}^{2}\right)$. The temperature and duration of the contact of the cube with the skin for inducing a third-degree burn were defined in the pilot study and verified histologically.

\section{Histological Examination}

After burn induction, the rats were kept for 14 days. During this time, 2 rats from each experimental group died. On day 14, the remaining rats were anesthetized using ketamine again. Then the surface area of the wound was measured using transparent checkerboard paper with a precision of $1 \mathrm{~mm}^{2}$ in a double-blind manner. The burn area was excised in full thickness with a $1-\mathrm{cm}$ margin and sent for histological study.

The samples were fixed in $10 \%$ formalin solution for $24 \mathrm{~h}$. Paraffin blocks were made and a $5-\mu \mathrm{m}$ longitudinal slice of the wound was provided by the tissue processor and stained with hematoxylin-eosin. Polymorphonuclear leukocyte (PMN), fibroblast, new vessel and monocyte counts, and percent of tissue in repair were recorded.

\section{Statistical Analysis}

The analysis was done by SPSS (version 15; SPSS, Chicago, Ill., USA). Values were expressed as means $\pm \mathrm{SD}$; the sample code 
Table 2. Characteristics of burn wounds 14 days after burn injury in control and experimental rats $(1 \mathrm{unit}=24 \mu \mathrm{m})$

\begin{tabular}{|c|c|c|c|c|c|c|c|c|c|c|c|}
\hline Characteristics & 1 & 2 & 3 & 4 & 5 & 6 & 7 & 8 & 9 & 10 & mean $\pm \mathrm{SD}$ \\
\hline Control group & 50 & 90 & 78 & 57 & 80 & 181 & 48 & 95 & 139 & 132 & $95 \pm 43.35$ \\
\hline Opium-dependent group & 144 & 45 & 138 & 88 & 123 & 66 & 95 & 124 & 203 & 188 & $120.4 \pm 50.12$ \\
\hline \multicolumn{12}{|c|}{ Length of re-epithelialized area ${ }^{\mathrm{b}}$, units } \\
\hline \multicolumn{12}{|c|}{ Thickness of re-epithelialized area ${ }^{c}$, units } \\
\hline Control group & 13 & 22 & 60 & 43 & 40 & 44 & 35 & 33 & 38 & 48 & $7.3 \pm 2.4$ \\
\hline Opium-dependent group & 90 & 40 & 48 & 30 & 65 & 41 & 50 & 12 & 80 & 88 & $6.1 \pm 2.18$ \\
\hline
\end{tabular}

${ }^{\mathrm{a}} \mathrm{t}=1.26$, d.f. $=18, \mathrm{p}=0.224{ }^{\mathrm{b}} \mathrm{t}=1.83$, d.f. $=18, \mathrm{p}=0.08{ }^{\mathrm{c}} \mathrm{t}=1.16$, d.f. $=18, \mathrm{p}=0.25$.

Table 3. Percentage of tissue repair in control and experimental rats

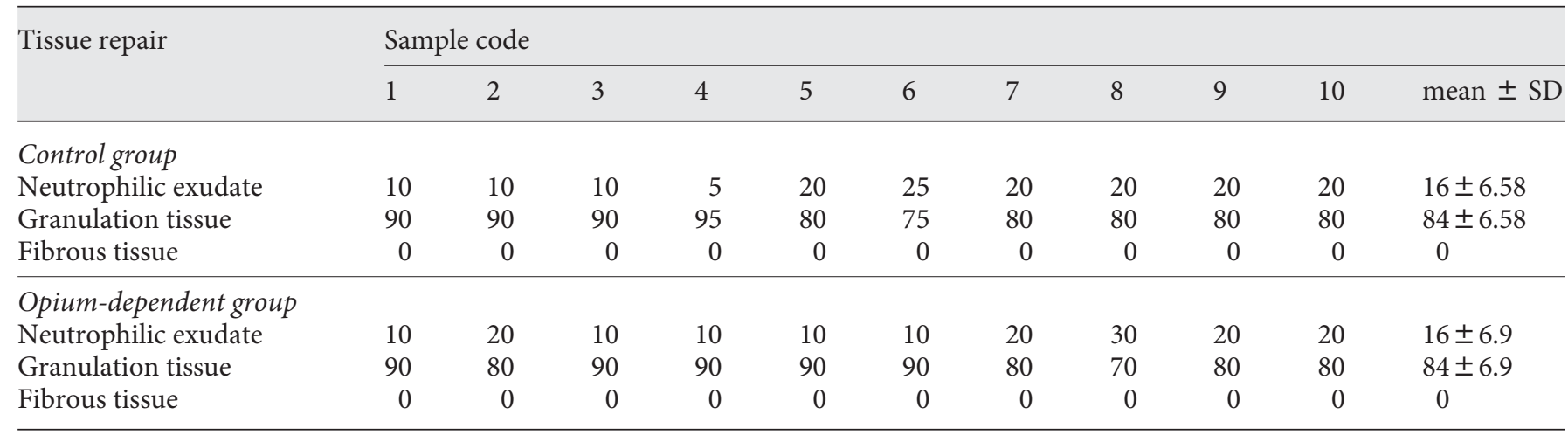

No significant differences were found between both groups.

represented the number of animals in experimental and control groups. A two-sample $t$ test was applied to compare means, and Fisher's exact probability test for nominal variables was used to compare two groups. Significance was accepted at $\mathrm{p}<0.05$. To compare naloxone-precipitated withdrawal symptoms, the $\chi^{2}$ test was used.

\section{Results}

\section{Opium Dependency}

Rats in the experimental group showed symptoms of naloxone withdrawal. Only 3 of 9 behavioral parameters were absent: writhing, jumping and paw tremor (table 1). The control group did not exhibit any of these symptoms.

Opium Dependency and Burn Healing

\section{Wound Characteristics and Microscopic Evaluation}

The surface area of wounds was $95 \pm 43.35 \mathrm{~mm}^{2}$ in the control group and $120.4 \pm 50.12 \mathrm{~mm}^{2}$ in the experimental group $(t=1.26$, d.f. $=18, p=0.224)$. The length of the re-epithelialization area was $37.6 \pm 13.17$ units in the controls and $54.4 \pm 25.82$ units in the experimental rats. One unit is equal to $24 \mu \mathrm{m}(\mathrm{t}=1.83$, d.f. $=18, \mathrm{p}=0.08)$. The thickness of the re-epithelialized area was $7.3 \pm 2.4$ $\mu \mathrm{m}$ in the controls and $6.1 \pm 2.18 \mu \mathrm{m}$ in the experimental group $(\mathrm{t}=1.16$, d.f. $=18, \mathrm{p}=0.25)$ (table 2$)$.

PMN count was $8.54 \pm 1.1$ in the controls and $5.41 \pm$ 3.9 in the experimental group $(\mathrm{t}=1.38$, d.f. $=18, \mathrm{p}=0.18)$. Fibroblast count was $71.44 \pm 16.47$ in the control group and $72.59 \pm 13.09$ in the experimental group $(t=0.86$, d.f. $=18, p=0.17)$. Mononuclear cell count was $9.02 \pm$ 
2.71 in the control and $6.69 \pm 1.94$ in the experimental group $(\mathrm{t}=2.2$, d.f. $=18, \mathrm{p}=0.041)$. The number of blood vessels was $4.55 \pm 1.76$ in the control group and $3.23 \pm$ 1.84 in the experimental group $(t=1.63$, d.f. $=18, p=$ 0.11 ).

Neutrophilic exudates, granulation tissue and fibrotic tissue were measured as indicators of healing. In the control group, $16 \pm 6.58 \%$ of the healing wounds were formed by neutrophilic exudate and $84 \pm 6.58 \%$ with granulation tissue. In the experimental group, $16 \pm 6.9 \%$ of the healing wound was formed by neutrophilic exudate and $84 \pm 6.9 \%$ with granulation tissue $(\mathrm{t}=0$, d.f. $=18$, $\mathrm{p}=1$ ). The wounds did not contain fibrotic tissue. Mononuclear cell count was significantly higher in the control group $(\mathrm{p}<0.05)$ (table 3$)$.

\section{Discussion}

This study investigated the effect of opium dependency on the healing process of third-degree burns in rats. A model for inducing a third-degree burn in rats was also offered. The model was verified histopathologically. Our findings indicate that opium dependency did not have a significant effect on the healing of burn wounds in rats. However, the number of monocytes was significantly different between both groups.

In a study by Lam et al. [8] in a mouse model of excisional wound injury, high-dose morphine impaired angiogenesis, increased systemic oxidative stress and impaired mobilization of endothelial progenitor cells. These findings reveal the potentially detrimental effect of morphine on wound healing. In another study in rats, morphine delayed wound closure when applied during the first 3 days, while no significant delay was observed when morphine was started after 3 days. Treatment of wounds with morphine reduced the number of myofibroblasts and macrophages in the closing wound significantly [9], being similar to our study in which the number of monocytes was lower in the opium-dependent group. However, in another study, topical opioids exerted positive effects on the healing of ischemic wounds in rats, especially during the first 4 days. Opioids also induced a $45-87 \%$ increase in angiogenesis [10]. Our findings did not support increased angiogenesis in opiumdependent rats.

However, an important difference between our and the above studies should be borne in mind when comparing results. The experimental rats in our study were opium dependent, thus differing from animals receiv- ing opium for a short term or at low doses. So any comparison of our findings with other studies must be made cautiously. Also, some other factors might have affected the results of our study. Whether degree and extent of burn, or dosage and type of opioids have influenced the results is to be clarified. Evidence indicates the impact of such parameters on the healing of wounds. For example, morphine is the main component of opium and morphine has been found to have the least healing property relative to fentanyl and hydromorphone [10]. Schwacha et al. [17] proposed that at a special size, a maximal level of burn injury may be reached so that opiates have no further detrimental effect. In this regard, studies comparing the effect of different sizes and grades of burn on wound healing can clarify the role of burn size and grade on the healing of burn wounds in opiumdependent rats.

\section{Conclusion}

Our findings did not reveal any association between opium dependency and third-degree burn healing in the rat, and morphine dependency does not seem to be as effective on third-degree burn healing.

\section{Acknowledgments}

We thank all the staff members in the Kerman Medical University Research Center who cooperated with us to implement this study.

References

1 Groohi B, Alaghehbandan R, Lari AR: Analysis of 1,089 burn patients in province of Kurdistan, Iran. Burns 2002;28:569-574

2 Aghakhani N, Rahbar N, Feizi A: Epidemiology of burn injuries in West Azerbaijan Province, Western Iran. Iran Red Cresc Med J 2009;11:85-89.

-3 Singer AJ, Clark RA: Cutaneous wound healing. N Eng J Med 1999;341:738-746.

4 Joranson DE, Ryan KM, Gilson AM, Dahl JL: Trends in medical use and abuse of opioid analgesics. JAMA 2000;283:1710-1714.

$\checkmark 5$ Prakash S, Fatima T, Pawar M: Patient-controlled analgesia with fentanyl for burn dressing changes. Anesth Analg 2004;99: $552-555$.

-6 Nakhaee N, Divsalar K, Meimandi MS Dabiri Sh: Estimating the prevalence of opiates use by unlinked anonymous urine drug testing: a pilot study in Iran. Subst Use Misuse 2008;43:513-520. 
7 Santos AP, Wilson AK, Hornung CA, Polk HC Jr, Rodriguez JL, Franklin GA: Methamphetamine laboratory explosions: a new and emerging burn injury. J Burn Care Rehabil 2005;26:228-232.

$>8$ Lam CF, Chang PJ, Huang YS, Sung YH, Huang CC, Lin MW, Liu YC, Tsai YC: Prolonged use of high-dose morphine impairs angiogenesis and mobilization of endothelial progenitor cells in mice. Anesth Analg 2008;107:686-692.

$\checkmark 9$ Rook JM, Hasan W, McCarson KE: Temporal effects of topical morphine application on cutaneous wound healing. Anesthesiology 2008;109:130-136.

10 Poonawala T, Levay-Young BK, Hebbel RP, Gupta K: Opioids heal ischemic wounds in the rat. Wound Repair Regen 2005;13:165174.
11 Flores LR, Wahl SM, Bayer BM: Mechanisms of morphine-induced immunosuppression: effect of acute morphine administration on lymphocyte trafficking. J Pharmacol Exp Ther 1995;272:1246-1251.

12 Roy S, Balasubramanian S, Sumandeep S, Charboneau R, Wang J, Melnyk D, Beilman GJ, Vatassery R, Barke RA: Morphine directs $\mathrm{T}$ cells toward $\mathrm{T}(\mathrm{H} 2)$ differentiation. Surgery 2001;130:304-309.

13 Ryan CM, Schoenfeld DA, Thorpe WP, Sheridan RL, Cassem EH, Tompkins RG: Objective estimates of the probability of death from burn injuries. N Engl J Med 1998;338: $362-366$.

14 Guide for the Care and Use of Laboratory Animals, Institute of Laboratory Animal Research, Commission on Life Sciences, National Research Council (http://www.nap. edu/catalog/5140.html).
15 Badawy AAB, Evans CM, Evans M: Production of tolerance and physical dependence in the rat by simple administration of morphine in drinking water. $\mathrm{Br} \mathrm{J}$ Pharmacol 1982;75:485-491.

16 Gellert VF, Holtzman SG: Development and maintenance of morphine tolerance and dependence in the rat by scheduled access to morphine drinking solution. Pharmacol Exp Ther 1978;205:536-546.

17 Schwacha MG, McGwin G, Hutchinson CB, Cross JM, Maclennan PA, Rue LW 3rd: The contribution of opiate analgesics to the development of infectious complications in burn patients. Am J Surg 2006;192:82-86. 